J.M.J., Vol. 4, No. 6)
December, 1951

\title{
STUDIES ON THE ANTITOXIC IMMUNITY OF DIPHTHERIA PART I
}

The Relationship between Circulating Antitoxin Titer of Actively Immunized Guinea Pigs and Their Tolerance to Toxin Intracutaneously Injected

MASAMI KUROKAWA, RYOSUKE MURATA, TAKESHI NAKANO, TAKAKKO YAMADA AND KENTARO KUBOTA

National Institute of Health, Tokyo, Japan

\section{INTRODUCTION}

It was reported in the preceding paper ${ }^{1)}$ that there is a correlation between the antitoxin content in the serum of a guinea pig actively immunized and the maximun amount of toxin that can be injected subcutaneously into the animal without causing death, or intracutaneously without causing skin reaction, though the individual variation existing between animals makes it difficult to establish such relation definitely. These results coincide with the reports by Schmidt ${ }^{2)}$, Glenny ${ }^{3)}$, Jerne ${ }^{4}$ ) etc. However, there are some experiments in our laboratory, a part of which was briefly described in the preceding paper'), suggesting that the relation between the antitoxin titer of serum and the amount of toxin to which the animal can tolerate is variable as the interval after the injection of toxoid varies.

This paper is dealing with the time of appearance and the duration of antitoxin in animals actively immunized and of their tolerance to toxin intracutaneously injected and the relation between the antitoxin titer and the tolerance to toxin thus obtained.

\section{MATERIALS AND METHODS}

Inoculation of toxoid:- A given dose of a crude or a highly purified toxoid was subcutaneously injected. The purified toxoid was diluted with $0.02 \%$ gelatine-borate-buffer, though it was not always suitable ${ }^{1)}$. The data of the purified toxoid used is abridged because it is of no importance in this paper ${ }^{1}$.

Antitoxin titration:- Antitoxin titration of serum was performed 
according to Jensen's intradermal rabbit method ${ }^{5}$ ) with some modifications for convenience. Test toxin is D-1, of which LR/100 was $0.0016 \mathrm{ml}$ and no significant variation of the test dose was observed throughout the whole experiments in this paper. In all experiments, the figures obtained were corrected basing upon the result of control test simultaneously performed with the Standard Serum. The logarithms of titer thus acquired were used in calculation of the parameters ${ }^{1)}$.

Quantitative Schcik test $\left.{ }^{3}\right)$ :- A series of intracutaneous injections into a guinea pig previously depilated in their back was performed with graded doses of a certain toxin, PSSC18 (MLD $=0.004 \mathrm{ml}, \mathrm{L}+=0.1 \mathrm{ml}, \mathrm{R} / 100=0.00083$ $\mathrm{ml}$ ), after bleeding for antitoxin titration. The series of test toxins was made by diluting with gelatine-borate-buffer solution, preserved with $0.01 \%$ sodium ethyl merculi thiosalicylate and stored in a refrigerator. The readings were made $40-48$ hours after the injections of the test toxins. The maximum toxin dose that did not produce any positive reaction beyond indistinct redness of $7-8 \mathrm{~mm}$ in diameter was taken as the titer of quantitative Schick test or the "neutralizing power" of the animal. The minimum dose of the toxin PSSC18, injected intracutaneously into a guinea pig and caused a reaction in the form of a small but distinct red flush $8-10 \mathrm{~mm}$ in diameter was $1 / 1000$ to $1 / 2000$ of 1 MLD of this toxin.

The bleedings for titration of antitoxin and quantitative Schick test were simultaneously performed with one of the animal groups at various times after the inoculation of toxoid, and the animal groups once were never used twice in this experiment.

"Neutralization index" :- The following is the method for calculating the figures which the authors call the "neutralization index" in this paper.

The unit of index was tentatively based on the relation of antitoxin titer to toxin dose in terms of Schick level. When an animal having 0.004 unit of antitoxin per $\mathrm{ml}$ of serum just neutralized 0.02 MLD of the toxin intracutaneously injected, the index was given as 1 . When the ratio of toxin dose neutralized to antitoxin content in serum was same as that of Schick level; for instances, if an animal having 0.02 unit or 0.0004 unit just neutralized 0.1 MLD or 0.002 MLD respectively, the index is also given as 1 . If the ratio of the toxin dose neutralized to antitoxin titer was different from this ratio, the index is obtained by dividing the toxin dose neutralized experimentally by the toxin dose which, if the index were 1 , 
the animal having same unit of antitoxin would neutralize. For instances, if an animal having 0.02 unit of antitoxin just neutralized 1 MLD or 0.01 MLD of the toxin, the index is given as $10.1=10$ or $0.010 .1=0.1$ respective1y. By means of this procedure, it seems that the relation between the antitoxin content in serum and the neutralizing power of animal would be clearly expressed.

\section{EXPERIMENT}

Groups Ia and Ib of Table 1 show the results of experiments in which the course of antitoxin production, the appearance of neutralizing power and their subsequent process were pursued periodically for months after the inoculation of toxoid. Group II of Table 1 shows the results of another

Table 1. Antitoxin titer and quantitative Schick test at different intervals after the inoculation of toxoid

\begin{tabular}{|c|c|c|c|c|c|}
\hline \multirow{2}{*}{$\begin{array}{l}\text { Groups } \\
\text { and } \\
\text { treat- } \\
\text { ments }\end{array}$} & \multirow[b]{2}{*}{$\begin{array}{c}\text { Intervals } \\
\text { in days }\end{array}$} & \multicolumn{2}{|c|}{ Antitoxin unit $/ \mathrm{ml}$. } & \multicolumn{2}{|c|}{ Quantitative Schick test } \\
\hline & & $\begin{array}{c}\text { Wean (number } \\
\text { of animals } \\
\text { tested) }\end{array}$ & $\begin{array}{c}\text { Limit of mean } \\
P=0.05\end{array}$ & $\begin{array}{c}\text { Mean (number } \\
\text { of animals } \\
\text { tested) }\end{array}$ & $\begin{array}{l}\text { Limit of mean } \\
P=0.05\end{array}$ \\
\hline $\begin{array}{c}\text { Ia } \\
\text { crude } \\
\text { toxoid } \\
\text { Lf }=30\end{array}$ & $\begin{array}{r}11 \\
18 \\
26 \\
33 \\
46 \\
68 \\
109 \\
175\end{array}$ & $\begin{array}{ll}0.001 & (6) \\
0.065 & (6) \\
0.16 & (6) \\
0.29 & (6) \\
0.21 & (6) \\
0.28 & (6) \\
0.25 & (6) \\
0.026 & (4)\end{array}$ & $\begin{array}{ll}0.15 & -0.029 \\
0.46 & -0.055 \\
0.52 & -0.16 \\
0.35 & -0.12 \\
0.4 .3 & -0.18 \\
0.4 & -0.15 \\
0.03 & -0.023\end{array}$ & $\begin{array}{l}5.5 \\
8.9 \\
0.72 \\
0.35 \\
0.21\end{array}$ & $\begin{array}{cc}21 & -1.5 \\
21 & -3.7 \\
2-1 & -0.25 \\
1.05 & -0.11 \\
0.35 & -0.12\end{array}$ \\
\hline $\begin{array}{c}\text { Ib } \\
\text { puri- } \\
\text { fied } \\
\text { toxoid } \\
\text { Lf }=30\end{array}$ & $\begin{array}{r}11 \\
18 \\
26 \\
33 \\
46 \\
68 \\
109 \\
175\end{array}$ & $\begin{array}{lr}0.001> & (6) \\
0.03 & (6) \\
0.053 & (6) \\
0.056 & (6) \\
0.085 & (6) \\
0.083 & (4) \\
0.14 & (6) \\
0.02 & (7)\end{array}$ & $\begin{array}{l}0.095-0.009 \\
0.22-0.013 \\
0.13-0.024 \\
0.17-0.044 \\
0.8-0.009 \\
0.55-0.033 \\
0.095-0.0042\end{array}$ & $\begin{array}{l}0.63 \\
1.35 \\
0.63 \\
0.051 \\
0.079\end{array}$ & $\begin{array}{ll}8 & -0.05 \\
9 & -0.2 \\
1.8 & -0.22 \\
0.19-0.015 \\
0.35-0.017\end{array}$ \\
\hline $\begin{array}{c}\text { II } \\
\text { crude } \\
\text { toxoid } \\
\text { Lf }=30\end{array}$ & $\begin{array}{l}10 \\
12 \\
14 \\
17 \\
19\end{array}$ & $\begin{array}{l}0.001> \\
0.001>(7) \\
0.003>\quad(6) \\
0.041 \\
0.083 \quad(6) \\
0 \quad(9)\end{array}$ & $\begin{array}{l}0.025-0.0005 \\
0.07-0.023 \\
0.16-0.043\end{array}$ & $\begin{array}{lr}0.005 & (7) \\
\text { too variable } \\
2.7 & (6) \\
3.7 & (9)\end{array}$ & $\begin{array}{l}0.01-0.002 \\
\text { to calculate } \\
\begin{array}{cc}6.5 & -1.1 \\
8 & -1.7\end{array}\end{array}$ \\
\hline
\end{tabular}

experiment in which the time of antitoxin production and of appearance of neutralizing power in early stage were observed in a little more detail. Combining the results of these experiments and that of several other experiments in which the antitoxin titration and quantitative Schick test were simultaneously performed, Fig. 1 was obtained, in which the antitoxin 
units and neutralizing powers of each animal were plotted against the days, and the means of the antitoxin unit and that of the neutralizing power for each time and the confidence intervals in which the mean of population would be contained at the $5 \%$ level of risk were illustrated.

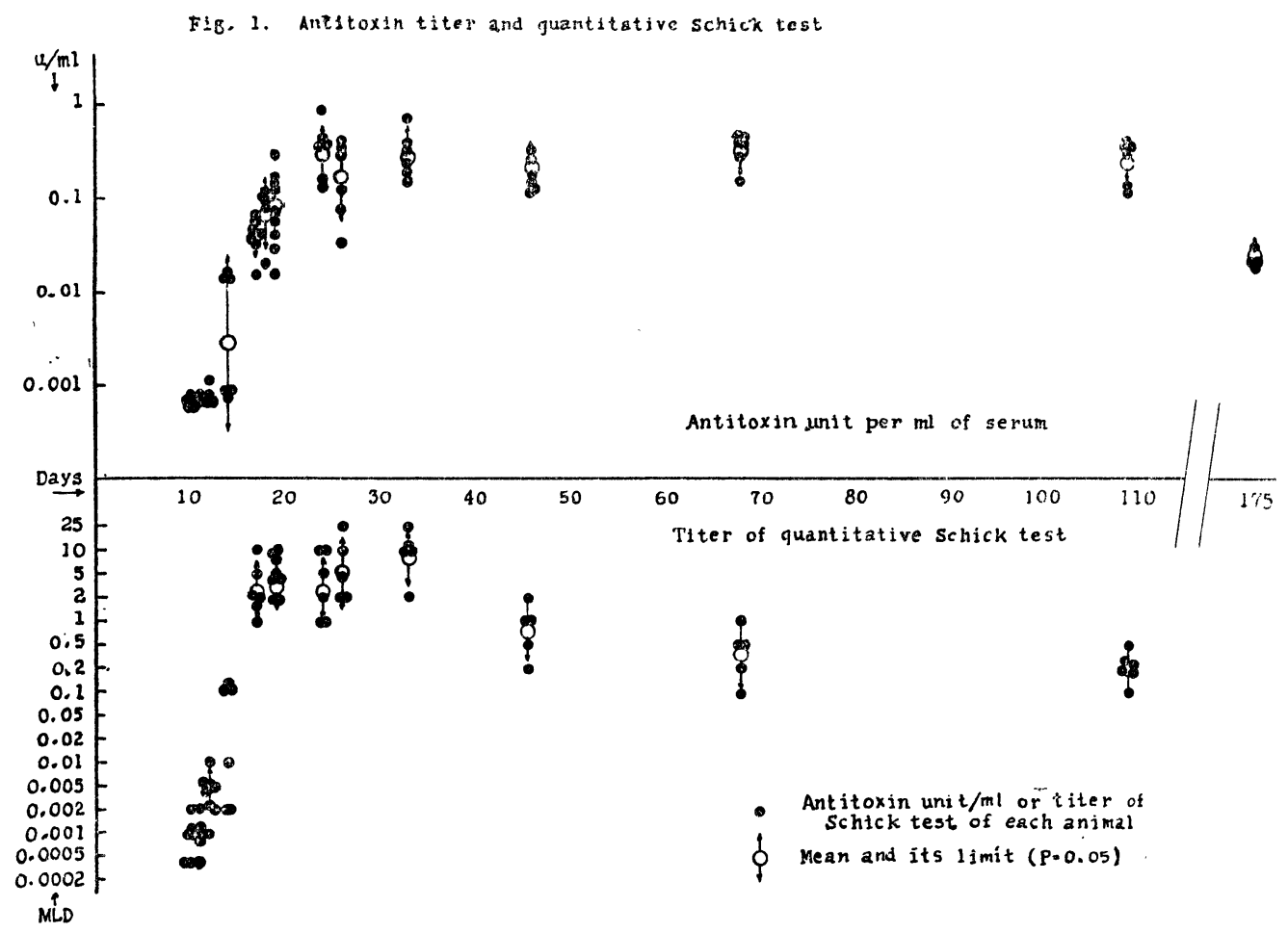

Followings may be concluded from Table 1 and Fig. 1.

The antitoxin became evidently detectable about 2 weeks after the inoculation of a certain toxoid dose. At this time, the effect of individuality was markedly observed, therefore, three out of six titrated animals had more than 0.01 unit per $\mathrm{ml}$ but other three were not detected to have 0.001 unit. Thereafter, the antitoxin titer increased rapidly to the maximum level in 3-4 weeks, which was maintained at least till 15 weeks under these experimental conditions. On the other hand, the neutralizing power to toxin intracutaneously injected was slightly detectable about 10 days after the inoculation of toxoid, and then increased rapidly to the maximum level within about 3 weeks which was maintained till 4-5 weeks. Thereafter the power decreased with comparative rapidity at first and slowly later 
or certain level appeared to persist. The effect of individuality was also markedly observed in the early stage. In other words, till 3-4 weeks after the inoculation of toxoid, the course of antitoxin production and that of appearance of neutralizing power were parallel or the latter might increase a little more rapidly, but thereafter a distinct divergent difference was observed between the antitoxin titer and the neutralizing power. No

Table 2. "Neutralization index" at different intervals after the inoculation of toxoid

\begin{tabular}{|c|c|c|c|}
\hline \multirow{2}{*}{$\begin{array}{c}\text { Intervals in } \\
\text { days }\end{array}$} & \multicolumn{3}{|c|}{ Neutralization index } \\
\hline & Mean (nu & als tested) & Limit of mean $P=0.05$ \\
\hline $\begin{array}{r}17 \\
19 \\
26 \\
33 \\
46 \\
60 \\
68 \\
109\end{array}$ & $\begin{array}{l}8.9 \\
8.7 \\
6.5 \\
5.5 \\
0.98 \\
0.23 \\
0.23 \\
0.18\end{array}$ & $\begin{array}{l}(6) \\
(9) \\
(9) \\
(12) \\
(10) \\
(5) \\
(9) \\
(11)\end{array}$ & $\begin{array}{cl}32 & -2.5 \\
15 & -5 \\
12.5 & -3.2 \\
9.8 & -3.1 \\
1.5 & -0.63 \\
0.59-0.094 \\
0.42-0.13 \\
0.27-0.11\end{array}$ \\
\hline
\end{tabular}

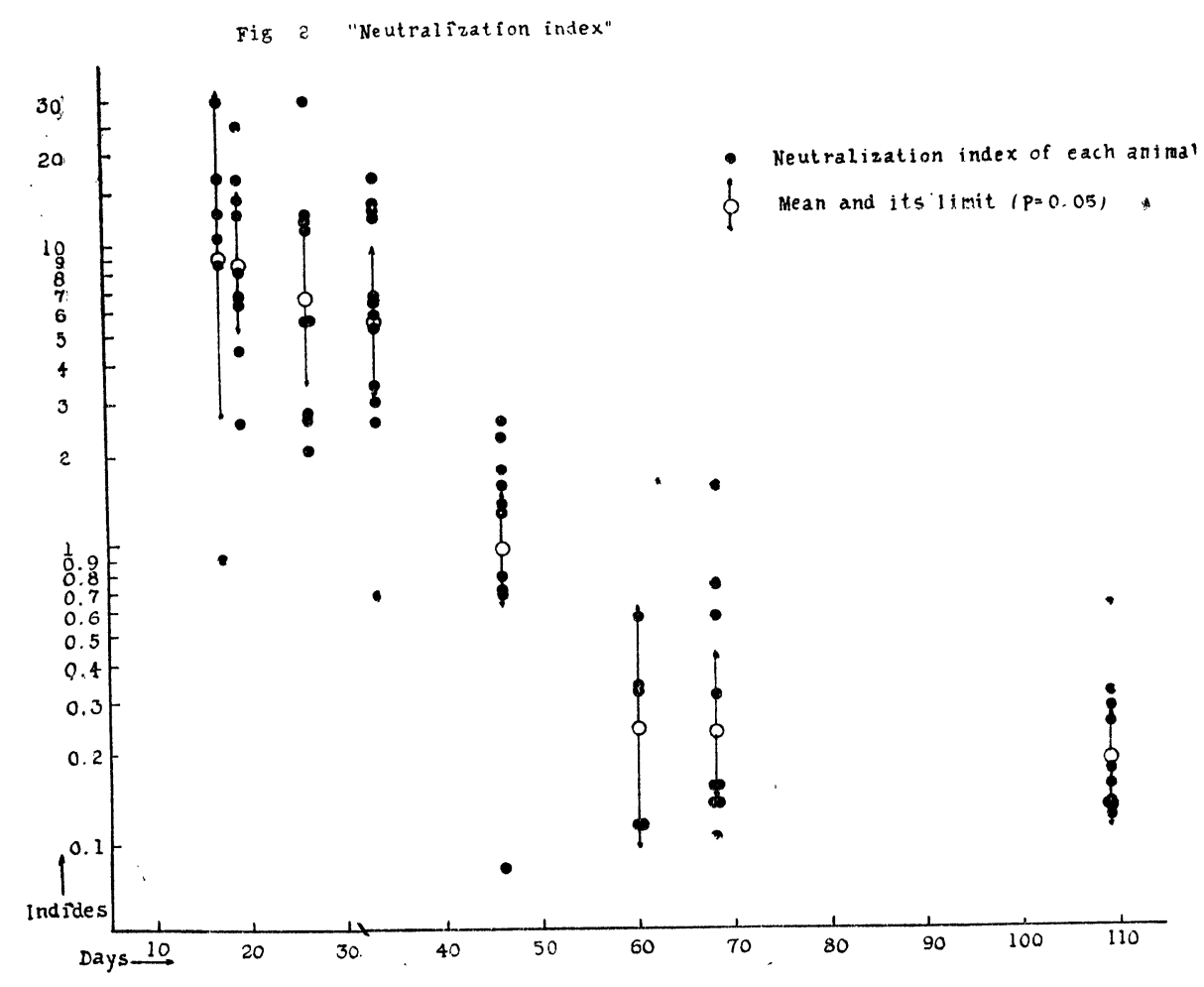


significant difference was observed between guinea pigs inoculated with crude toxoid and those inoculated with highly purified toxoid in respect to the course of antitoxin production, the appearance of neutralizing power and their mutual relation.

These relations are better demonstrated in Table 2 and Fig. 2 in which neutralization indices were illustrated. The confidence intervals, in which the mean neutralization index of population would be contained, were from 2.5 to 30 , from 0.6 to 1.5 and from 0.1 to 0.6 at the time during the period of 17-34 days, at 46 days and at the time during the period 60-109 days after inoculation of toxoid respectively.

\section{DISCUSSION}

1) The view that an animal having Schick level, or $1 / 250$ of a unit of antitoxin per $\mathrm{ml}$ of serum will just neutralize 1,50 of an MLD of toxin intracutaneously injected seems to be true only at a certain time and in a rather narrow range of period after the inoculation of toxoid in guinea pigs. The shorter the interval after toxoid inoculation became, the more the toxin was neutralized, than that expected from the relation between antitoxin titer and toxin dose in terms of Schick level and the longer the interval became, the less the toxin was neutralized.

2) It may be too hasty to generalize this result to human being without any experiments, but the significance of Schick test in antitoxic immunity of human being, or the relation between the antitoxic titer and the immunity to diphtheria infection naturally or artificially induced, etc seem to be reexamined basing on the renewed view point. An assumption explaining the somewhat confused relation between the Schick reaction and antitoxic titer may be born from these results. In respect to this point, Phair's view ${ }^{6}$ is interesting that the Schick test differentiates the individuals who have no demonstrable circulating antitoxin and those who cannot rapidly mobilize antitoxin when they are given minute stimulus. But there would be no evidence that the antitoxin alone must be considered. If the antitoxic titer induced naturally or artificially does not always linearly show the immunity to infection, the method which is able to demonstrate the true aspect of the antitoxic immunity should be deviced.

3) The problem why the neutralizing power begins to decrease in a relatively early stage while antitoxin titer is maintained for longer period 
of time, are under investigations in our laboratory and will be reported in separate papers.

Not a single report observing similar phenomena to such as above described with reference to antitoxic immunity seems to have ever been published. In the case of neurotropic viruses, the reports that the circulating protective antibody and immunity to infection of animals actively immunized are not always in parallel, that the circulating protective antibody does not always indicate the immunity to infection, that the immunity appears in an early stage and begins to decrease when the circulating protective antibody reached the maximum, and that the neutralizing power is maintained for longer period of time but the immunity markedly decreases in the early stage etc have been presented, for instances, by Olitzky and $\operatorname{Cox}^{(7)}$, Sabin and Olitzky ${ }^{8)}$, Webster $^{(9)}$, Hodes and Webster ${ }^{10)}$, Casals ${ }^{11}$, Nakazawa ${ }^{12)}$ etc.

4) The question as to whether the same results are obtainable or not in the cases when the toxin is inoculated intracutaneously as above or subcutaneously remains unsolved. There are a few experiments concerning with this problem, but the number of animals is still too small to make any definite statement. However, unless this problem is resolved, it should be kept in mind that the time interval between inoculation of toxoid and toxin may possibly affect the result of potency tes .

5) It was observed that most guinea pigs were showing more than 0.01 unit of antitoxin per m1 17-18 days after the inoculation of a certain dose of toxoid. As antitoxin titer required to resist $10 \mathrm{MLD}$ of the toxin subcutaneously injected into animal, was about 0.002 unit per $\mathrm{ml}^{11}$, most animals inoculated with a certain dose of toxoid would become tolerable to the challenge with 10 MLD of toxin by this time.

\section{SUMMARY AND CONCLUSION}

1) The circulating antitoxin titer of the guinea pigs inoculated with a certain dose of toxoid becomes detectable about 2 weeks after the inoculation of toxoid and reaches the maximum level in 4 weeks or so, which is maintained for months.

2) The neutralizing power of the majority of the guinea pigs treated in the same manner as above becomes detectable about ten days after the inoculation of toxoid, reaches the maximum level approximately within 3 
weeks and the level is maintained for 1-2 weeks or so thereafter, and then decreases with comparative rapidity to a certain level which appears to persist thereafter.

3) Thus, a striking difference is noticed in the relation of the circulating antitoxin titer to the neutralizing power against toxin intracutaneously injected as the time interval between inoculation of toxoid and the titration varies.

4) From the results above obtained, several problems concerning to the significance of antitoxin titer or Schick test in the antitoxic immunity were introduced.

\section{POST SCRIPT}

1) As the basis for calculation of the "neutralization index", the relation of antitoxin titer to LR of the toxin PSSC18 is considered to be more reasonable. The neutralization indices calculated on this basis correspond to the figures obtained by means of multiplying these in this paper by 0.25 .

2) Before the printing has been completed Dr. Jerne's work, “A study of avidity", was published, in which there are some suggestions that the discrepancies in "neutralization index" may be explained by the change in avidity of sera. This problem is under study.

\section{REFERENCES}

1) Kurokawa, M., Murata, R., Nakano, T., Yamada, T. and Kubota, K.: On the antigenicity of diphtheria toxoid. Part I. Titration of immunizing potency. Jap. Med. J., 4, 1, 55-70, 1951.

2) Schmidt, S. and Fjord-Nielsen, I.: Ueber die Relation zwischen Antitoxingehalt und Toxinresistanz nach aktiven immunisierung gegen Diphtherietoxin. Z. Immunitätsf., 81, 473-478, 1933-34.

3) Glenny, A.T. and Waddington, H.: The Schick reaction and circulating antitoxin. Connection between tolerance for toxin and presence of circulating antitoxin. J. Path. Bact., 32, 275-281, 1929.

4) Jerne, N.K. and Maal $\phi$ e, O.: Standardisation de l'anatoxine diphthérique. Quelques considerations théoriques et pratiques. Bull. Org. Mond. Santé, 2, 49-57, 1949.

5) Jensen, C.: Die intrakutane Kaninchenmethode zur Anwendung von Diphtherietoxin und Diphterieantitoxin. Acta. Path. Microb. Scand., Suppl. 14, 1933.

6) Phair, J.J.: Diphtheria immunization: The interpretation of the Schick test. Am. J. Hyg., 36, 283-293, 1946.

7) Olitzky, P.K. and Cox, H.R.: Experiments on active immunizationagai nst experimental poliomyolitis. J. Exp. Med., 63, 109-125, 1936. 
8) Sabin, B. and Olitzky, P.K.: Humoral antibodies and resistance of vaccinated and convalescent monkeys to poliomyelitis virus. J. Exp. Med., 64, 739-748, 1936.

9) Webster, L.T.: A mouse test for measuring the immunizing potency of antirabies vaccines. J. Exp. Med., 70, 87-106, 1939.

10) Hodes, H. L. and Webster, L.T.: Relation between degree of immunity of mice following vaccination with St, Louis encephalitis virus and the titre of the protective antibodies of the serum, J. Exp. Med., 68, 263$271,1937$.

11) Casals, J.: Neutralizing and complement-fixing antibody production and resistance following vaccination in experimental encephalitis infections. J. Exp. Med., 78, 447-463, 1943.

12) Nakazawa, S.: Time of apparance and duration of immunity and circulating protective antibody following vaccination with rabbit brain infected with rabies. Saikingaku Zasshi, No. 579 192-211; No. 582, 270-281, 1944 (in Japanese). 